\title{
Effects of galantamine and galantamine combined with nimodipine on cognitive speed and quality of life in mixed dementia: a 24- week, randomized, placebo-controlled exploratory trial (the REMIX study)
}

Efeitos da galantamina e da galantamina combinada à nimodipina sobre a velocidade de processamento cognitivo e qualidade de vida na demência mista: ensaio clínico exploratório, randomizado e controlado com placebo (estudo REMIX)

Paulo Caramelli', Jerson Laks², André Luis Fernandes Palmini ${ }^{3}$, Ricardo Nitrini ${ }^{4}$, Márcia Lorena Fagundes Chaves ${ }^{5}$, Orestes Vicente Forlenza ${ }^{6}$, Francisco de Assis Carvalho do Vale ${ }^{7}$. Maira Tonidandel Barbosa ${ }^{1,8}$, Cássio Machado de Campos Bottino ${ }^{9}$, João Carlos Machado ${ }^{8}$. Helenice CharchatFichman ${ }^{10}$, Fabio Lorea Lawson ${ }^{11}$

\begin{abstract}
The effects of galantamine (GAL) on quality of life (QoL) and cognitive speed, as well its effects combined with nimodipine (NIM) in Alzheimer disease (AD) with cerebrovascular disease (mixed dementia), have not been explored. Method: Double-blind, placebo-controlled, multicenter Brazilian trial, studying the effects of GAL/NIM vs. GAL/placebo (PLA) in mild to moderate mixed dementia. Patients were randomized to receive GAL/NIM or GAL/PLA for 24 weeks. Primary efficacy measures were changes on a computerized neuropsychological battery (CNTB) and QoL Scale in Alzheimer's Disease (QoL-AD) from baseline to week 24. Results: Twenty-one patients received at least one drug dose (9 GAL/NIM and 12 GAL/PLA). Groups were matched for age, sex, education, cognitive and QoL scores at baseline. No significant differences were observed between groups on primary or secondary measures. QoL and cognitive performance showed significant improvement $(p<0.05)$ from baseline when all GAL-treated patients were analyzed. Adverse events were predominantly mild to moderate. Conclusion: GAL treatment improved QoL in mixed dementia, in addition to its previously known cognitive benefits. The combination GAL/ NIM was not advantageous. However, the small sample size precludes any definitive conclusions. Trial registered at ClinicalTrials.gov: NCT00814658
\end{abstract}

Keywords: Alzheimer disease, cerebrovascular disorders, galantamine, nimodipine.

RESUMO

Os efeitos da galantamina (GAL) sobre qualidade de vida (QdV) e velocidade de processamento cognitivo, bem como da combinação com nimodipina (NIM) no tratamento da doença de Alzheimer (DA) com doença cerebrovascular (demência mista) ainda não foram investigados. Método: Estudo multicêntrico brasileiro, duplo-cego, controlado com placebo, avaliando os efeitos de GAL/NIM x GAL/placebo (PLA) na demência mista leve a moderada. Pacientes receberam tratamento com GAL/NIM ou GAL/PLA por 24 semanas. Medidas de eficácia primária foram as variações no desempenho em bateria de testes neuropsicológicos computadorizados e na escala QdV-DA ao final do

${ }^{1}$ Departamento de Clínica Médica, Faculdade de Medicina, Universidade Federal de Minas Gerais, Belo Horizonte MG, Brazil;

${ }^{2}$ Centro de Doença de Alzheimer e outras Desordens Mentais na Velhice, Instituto de Psiquiatria, Universidade Federal do Rio de Janeiro, Rio de Janeiro RJ, Brazil;

${ }^{3}$ Serviço de Neurologia, Pontifícia Universidade Católica do Rio Grande do Sul, Porto Alegre RS, Brazil;

${ }^{4}$ Departamento de Neurologia, Faculdade de Medicina, Universidade de São Paulo, Sao Paulo SP, Brazil;

${ }^{5}$ Serviço de Neurologia, Hospital de Clínicas de Porto Alegre, Universidade Federal do Rio Grande do Sul, Porto Alegre RS, Brazil;

${ }^{6}$ Laboratório de Neurociências LIM-27, Departamento e Instituto de Psiquiatria, Faculdade de Medicina, Universidade de São Paulo, Sao Paulo SP, Brazil;

${ }^{7}$ Liga de Neurologia Cognitiva e Comportamental, Universidade Federal de São Carlos, Sao Carlos SP, Brazil;

${ }^{8}$ Instituto de Ensino e Pesquisa do Envelhecimento, Departamento de Medicina Geriátrica, Hospital Mater Dei; Faculdade de Ciências Médicas de Minas Gerais, Belo Horizonte MG, Brazil;

${ }^{9}$ Programa Terceira Idade, Departamento e Instituto de Psiquiatria, Faculdade de Medicina, Universidade de São Paulo, Sao Paulo SP, Brazil;

${ }^{10}$ Pontifícia Universidade Católica do Rio de Janeiro, Rio de Janeiro RJ, Brazil;

${ }^{11}$ Janssen-Cilag Farmacêutica Ltda., Sao Paulo SP, Brazil.

Correspondence: Paulo Caramelli; Av. Prof. Alfredo Balena, 190 / Sala 246; 30130-100 Belo Horizonte MG, Brasil; E-mail: caramelli@ufmg.br

Conflict of interest: This study and the present communication were supported by Janssen-Cilag Farmacêutica Ltda., São Paulo, Brazil. 
estudo. Resultados: Vinte um pacientes receberam pelo menos uma dose da droga (9 GAL/NIM e 12 GAL/PLA). Os grupos foram emparelhados por idade, sexo, escolaridade, escores cognitivos e de QdV na linha de base. Não foram observadas diferenças significativas entre os dois grupos nas medidas de eficácia primária e secundária. Na avaliação de todos os pacientes que receberam GAL, houve melhora significativa $(p<0,05)$ em QdV-DA e desempenho cognitivo. Os eventos adversos foram predominantemente leves a moderados. Conclusão: O tratamento com GAL proporcionou melhora da QdV na demência mista, além dos benefícios cognitivos previamente conhecidos. A combinação GAL/NIM não foi vantajosa. O reduzido tamanho amostral impede conclusões definitivas.

Palavras-chave: doença de Alzheimer, desordens cerebrovasculares, galantamina, nimodipina.

Mixed dementia (defined as an association of both Alzheimer disease - AD - and cerebrovascular disease CVD) is a common cause of dementia worldwide ${ }^{1}$. It is usually underdiagnosed and, according to a Brazilian study, mixed dementia is the second most frequent cause of dementia among people aged $\geq 65$ years in the country, being responsible for circa $14 \%$ of all cases ${ }^{2}$.

There is still a lack of well-established therapeutic options for patients with this condition based on high quality evidence. Most studies have investigated the efficacy and safety of different agents on each condition separately ( $\mathrm{AD}$ or $\mathrm{CVD})^{3,4,5}$, even though the association of $\mathrm{AD}$ and $\mathrm{CVD}$ is well documented in the medical literature ${ }^{6}$.

Ischemic lesions seem to play a prominent role in cognitive decline, even in the presence of $\mathrm{AD}$ pathology. Cholinesterase inhibitors (ChEIs), especially galantamine (GAL), proved to be effective in the treatment of $\mathrm{AD}^{5}$ and also in the treatment of patients with mixed dementia $(\mathrm{AD}$ with $\mathrm{CVD})^{7}$. In a study with rivastigmine, patients with $\mathrm{AD}$ and concurrent vascular risk factors had more benefits on cognition and functional performance than patients without concurrent vascular risk factors ${ }^{8}$.

GAL has demonstrated beneficial effects on both cognitive and non-cognitive outcomes in patients with $\mathrm{VaD}$ and in $\mathrm{AD}$ with $\mathrm{CVD}^{9,10}$. GAL is the only ChEI approved for treatment of patients with $\mathrm{AD}$ with CVD in Brazil and in some other countries. However, its effects on quality of life (QoL) and cognitive speed in patients with mixed dementia have not been investigated so far. Moreover, the efficacy of GAL treatment combined with nimodipine (NIM), a calcium channel antagonist with putative neuroprotective effects in patients with subcortical vascular dementia, has not been explored. NIM improves cerebral blood flow via its vasodilatory effects, and, by restricting the influx of calcium ions into neurons, may prevent neuronal apoptosis ${ }^{11}$. A few studies have found evidence that NIM provides some short-term benefits, mainly in measures of cognitive function and global impression ${ }^{3}$.

Received 20 February 2014; Received in final form 08 March 2014; Accepted 31 March 2014
The aim of the present exploratory study was to compare GAL plus NIM vs. GAL alone on cognitive speed and QoL measures in patients with mixed dementia.

\section{METHOD}

\section{Study design}

This was a double-blind, placebo-controlled, exploratory, parallel study involving 11 centers in four Brazilian states (Minas Gerais, Rio de Janeiro, Rio Grande do Sul, and São Paulo), conducted from May, 2008 to October, 2009. Patients were randomized (1:1) to one of two treatment arms: GAL (16-24 mg/day) plus NIM (90 mg/day) or GAL (16-24 mg/day) plus placebo (PLA). Both groups were followed for 24 weeks. GAL dose was started at $8 \mathrm{mg}$ QD, with monthly increments up to $24 \mathrm{mg}$ QD if well-tolerated, for both arms. NIM dose was $30 \mathrm{mg}$ three times a day (TID) throughout the study and PLA was also given TID. Patients were submitted to six clinical evaluations throughout the study: enrollment visit, baseline, and follow-up visits at $4,8,16$ and 24 weeks after baseline.

The simple random allocation sequence was performed using the PLAN procedure of SAS software, Version 9.1.3 (SAS Institute Inc., Cary, NC, USA). Each patient, at the enrollment, received a randomization number and the corresponding numbered medication. To ensure the blinding was maintained (for both patients and study team), the medication was provided into recipients as tablets $(8 \mathrm{mg}$, $16 \mathrm{mg}, 24 \mathrm{mg}$ of GAL and $30 \mathrm{mg}$ of NIM or PLA) that were similar in size and appearance. The study was performed under the Good Clinical Practice regulations and according to the Declaration of Helsinki. The protocol and the informed consent for patients and caregivers were approved by the Institutional Review Board of each site. Written informed consent from patients and their responsible relatives was required prior to enrollment.

The key co-primary efficacy measures were change from baseline to week 24 in cognitive speed and on QoL. The secondary endpoints were: (1) global cognitive performance; (2) global clinical impression; and (3) neuropsychiatric symptoms. Two separate analyses were performed considering the pilot study nature of this trial: between treatment 
groups' comparison (GAL/NIM vs. GAL/PLA) and changes in efficacy measures from baseline to end of follow-up (within group comparison).

\section{Study patients}

Patients were eligible to be included in the trial if they met the following criteria: (1) men or women outpatients; (2) age $\geq 65$ years; (3) fulfilling DSM-IV diagnostic criteria for dementia ${ }^{12}$; (4) fulfilling NINDS-AIREN diagnostic criteria for AD with CVD (mixed dementia) ${ }^{13}$; (5) mild to moderate dementia, with Mini-Mental State Examination (MMSE) ${ }^{14}$ scores ranging from 10 to 26, inclusive; (6) presence of a caregiver; (7) signed informed consent provided by patients and/or their legally-accepted representatives. Patients had to present significant CVD on magnetic resonance imaging, namely the presence of cortical lesions and/or subcortical lesions (periventricular and deep white matter changes) affecting at least $25 \%$ of the subcortical area.

The following exclusion criteria were adopted: (1) illiteracy; (2) any other neurodegenerative disorder, such as Parkinson's disease, frontotemporal dementia, Huntington's disease, Down syndrome, or Creutzfeldt-Jakob disease; (3) current or past (last six months) clinical history of hepatic or renal failure, history of significant cardiac, pulmonary, gastrointestinal, endocrine, metabolic, neurologic or psychiatric disturbances; or of urinary flow obstruction; (4) cognitive impairment resulting from acute cerebral trauma, hypoxic cerebral damage, vitamin deficiency states, infections, primary or metastatic brain tumor, endocrine or metabolic disease, mental retardation or oligophrenia; (5) use of benzodiazepines or antiepileptic drugs in the last three months; (6) use of any experimental treatment (for dementia or any other condition) in the last 12 months; (7) history of drug or alcohol abuse; (8) participation in previous studies with GAL; and (9) history of known allergy or hypersensitivity to ChEIs. Patients who had taken ChEIs or memantine in the past could participate in the trial if the drug was discontinued at least 30 days before the first evaluation.

\section{Outcome measures}

Primary efficacy measures were performed using a computerized neuropsychological battery $(\mathrm{CNTB})^{15,16}$ and the scores on a QoL measure (the QOL Scale in Alzheimer's Disease, QoL-AD) $)^{17,18}$ at the end of the $24^{\text {th }}$ week of treatment. The CNTB included tasks assessing attention and memory (simple and double-choice reaction tasks, face recognition and word-list learning tasks) assessed as reaction times expressed in milliseconds. QoL-AD includes three versions: two caregiver's versions (about patients' and their own perceived QoL) and a patient's version. The scale is composed of 13 items that measure the domains of physical condition, mood, memory, functional abilities, interpersonal relationships, ability to participate in meaningful activities, financial situation, and global assessments of self as a whole and QOL as a whole. Each item is assessed on a 4-point scale ( $1=$ poor, $4=$ excellent). Scale scores range from 13 to 52, with higher scores indicating greater QOL.

Secondary efficacy measures were: Alzheimer's disease Assessment Scale-Cognitive Subscale (ADAS-Cog) $)^{19,20}$, Clinician Global Impression Improvement Scale (CGI-I) ${ }^{21}$, Neuropsychiatric Inventory (NPI ${ }^{22,23}$ and Mini-Mental State Examination (MMSE) $)^{14,24}$. Tolerability was assessed based on the rate and severity of investigator-recorded adverse events.

\section{Statistical analysis}

The intention-to-treat population for efficacy and safety included all patients who received at least one dose of the study medication and had at least one safety evaluation after the first visit. An exploratory approach was adopted since similar studies with both drugs and assessing the same outcomes were not available to our knowledge. Thus, expected effect size to use in sample size calculation could not be obtained from the literature and the investigators assumed that 40 patients enrolled in each arm should be sufficient to derive robust estimations of clinical benefit in this pilot study. Efficacy was analyzed as the difference in mean change from baseline to endpoint between treatment groups and within groups for the CNTB, QoL-AD, ADAS-Cog, CGI-I, NPI, and MMSE scores. Repeated Measures Analyses of Variance were employed to both between-group and within-group comparisons. All statistical tests assumed a $5 \%$ level of significance.

\section{RESULTS}

Twenty-one patients were enrolled and randomized and received at least one dose of the proposed drug regimen: 9 in the GAL/NIM group and 12 in the GAL/PLA group. The study did not reach the expected sample size mainly due to the strict eligibility criteria established to ensure that only mixed dementia patients would be enrolled. No differences between the two groups were observed in terms of age $(\mathrm{p}=0.172)$, gender distribution $(\mathrm{p}=0.331)$ and educational level $(\mathrm{p}=0.464)$ (Table 1). Baseline MMSE scores, CNTB measures, QoL, ADAS-Cog and NPI scores were also similar between the two groups (Table 2). Five patients (55.6\%) in the GAL/NIM and $8(66.7 \%)$ in the GAL/PLA group completed the study. Reasons for dropout were: 4 due to adverse events (in visit 3); 2 due to adverse event and 1 medical criteria (in visit 4); 1 due to lost to follow up (visit 6) (Figure 1). 
Table 1. Baseline sociodemographic and clinical characteristics of the study participants.

\begin{tabular}{lccc}
\hline Variable (mean \pm SD) & $\begin{array}{c}\text { GAL/NIM } \\
(n=9)\end{array}$ & $\begin{array}{c}\text { GAL/PLA } \\
(n=12)\end{array}$ & Total sample \\
\hline Age & $78.1 \pm 5.3$ & $74.3 \pm 6.5$ & $76.0 \pm 6.2$ \\
Sex & $5 \mathrm{~F}: 4 \mathrm{M}$ & $10 \mathrm{~F}: 2 \mathrm{M}$ & $15 \mathrm{~F}: 6 \mathrm{M}$ \\
Years of education & $5.0 \pm 3.3$ & $4.0 \pm 2.7$ & $4.4 \pm 2.9$ \\
Disease duration (months) & $29.8 \pm 33.0$ & $5.6 \pm 10.8$ & $14.5 \pm 24.1$ \\
Subcortical vascular disease $-\mathrm{n}(\%)$ & $8(88.9 \%)$ & $12(100 \%)$ & 0.331 \\
MMSE & $15.4 \pm 5.6$ & $17.9 \pm 3.8$ & 0.464 \\
\hline
\end{tabular}

GAL: galantamine; NIM: nimodipine; PLA: placebo; SD: standard deviation; MMSE: Mini-Mental State Exam.

Table 2. Results for the computerized neuropsychological battery test components, reaction times (milliseconds).

\begin{tabular}{|c|c|c|c|c|c|}
\hline Outcome measure & & GAL/NIM & GAL/PLA & Total sample & $\mathrm{p}$-value \\
\hline \multirow[t]{3}{*}{ Simple-choice reaction time Test $(n=12)$} & Baseline & $1,208.7 \pm 1,670.0$ & $646.7 \pm 314.8$ & $880.9 \pm 1,073.3$ & \multirow{2}{*}{$0.337 *$} \\
\hline & 24-weeks & $467.6 \pm 336.7$ & $618.7 \pm 329.8$ & $555.7 \pm 326.5$ & \\
\hline & & Within-group change & & -325.2 & $0.303 * *$ \\
\hline \multirow[t]{3}{*}{ Two-choice reaction time Test $(n=12)$} & Baseline & $1,785.5 \pm 1,793.7$ & $1,279.5 \pm 696.7$ & $1,490.3 \pm 1,225.8$ & \multirow{2}{*}{$0.274^{*}$} \\
\hline & 24-weeks & $727.6 \pm 375.0$ & $1,197.9 \pm 528.3$ & $1,001.9 \pm 511.9$ & \\
\hline & & Within-group change & & -488.4 & $0.207 * *$ \\
\hline \multirow[t]{3}{*}{ Face Recognition Test $(n=11)$} & Baseline & $2,890.2 \pm 1,432.1$ & $3,168.8 \pm 943.0$ & $3,067.5 \pm 1,081.0$ & \multirow{2}{*}{$0.256 *$} \\
\hline & 24-weeks & $1,730.7 \pm 1,514.1$ & $3,148.1 \pm 1,964.3$ & $2,632.7 \pm 1,874.6$ & \\
\hline & & Within-group change & & -434.8 & $0.240 * *$ \\
\hline \multirow[t]{2}{*}{ Word Recognition and Learning Test $(n=12)$} & Baseline & $2,166.1 \pm 715.4$ & $3,387.3 \pm 2,214.0$ & $2,878.4 \pm 1,804.2$ & \multirow[t]{2}{*}{$0.859 *$} \\
\hline & 24-weeks & $\begin{array}{l}1,722.0 \pm 1,174.2 \\
\text { Within-group change }\end{array}$ & $3,104.6 \pm 1,328.3$ & $\begin{array}{c}2,528.5 \pm 1,403.8 \\
-349.9\end{array}$ & \\
\hline
\end{tabular}

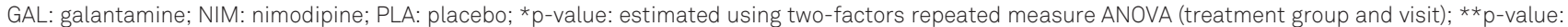
estimated using single-factor repeated measure ANOVA (visit).

\section{Efficacy}

For the between-group comparison (GAL/NIM vs. GAL/ PLA), no significant differences on primary efficacy measure were found on the CNTB (Table 2) and QoL-AD (Table 3). The secondary efficacy endpoint findings were also similar between GAL/NIM and GAL/PLA, with no statistical significance in between-group comparisons for the ADASCog, CGI-I, MMSE or NPI, suggesting that adjunctive NIM did not contribute to additional benefits (Table 4). Thus, further analyses were developed for efficacy measures using the

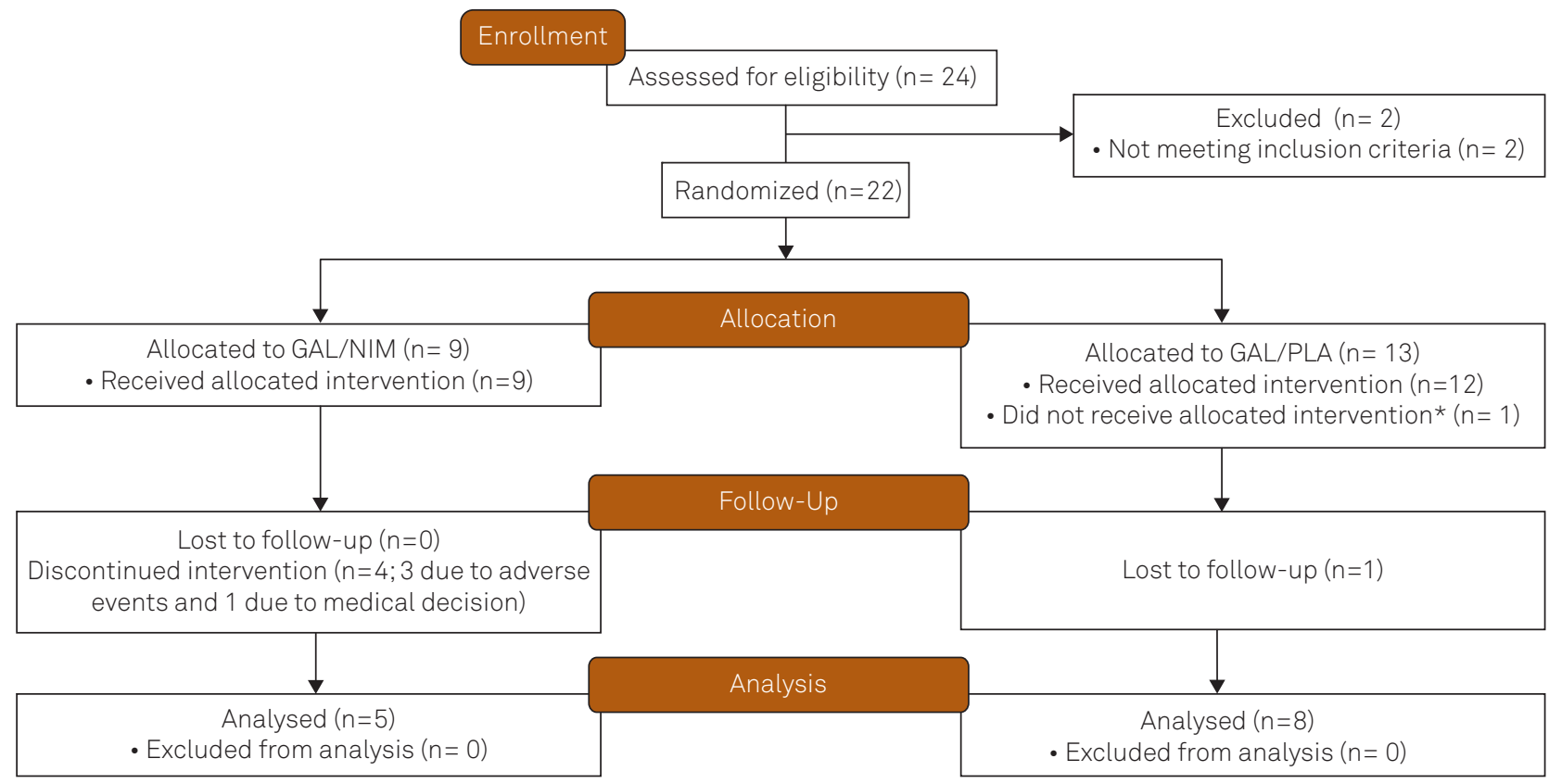

${ }^{*}$ One patient changed treatment arm for a short period during the study and was excluded from the analysis.

Figure. CONSORT 2010 Study Flow Diagram. 
Table 3. Results for the QoL-AD questionnaire, total scores.

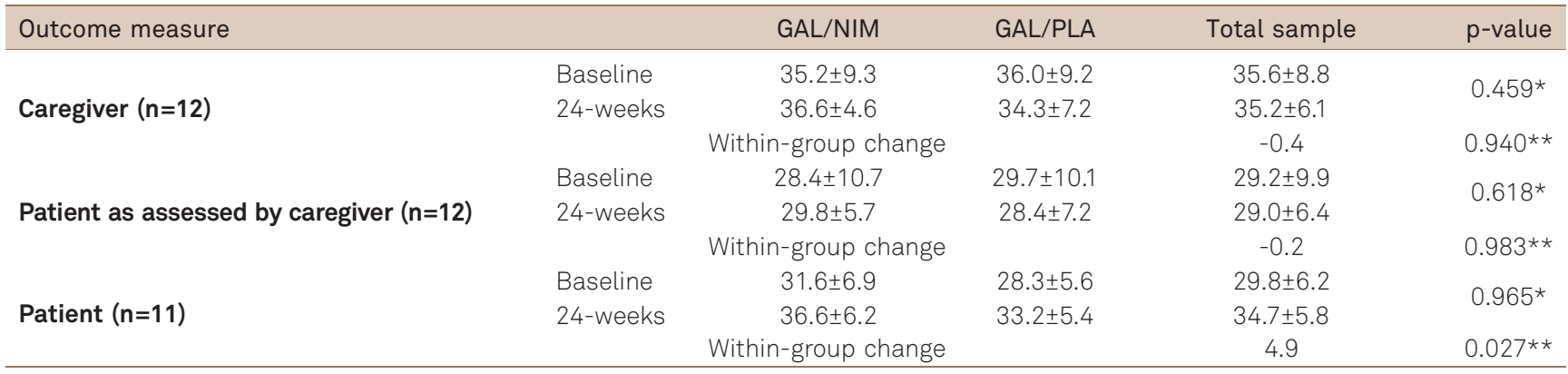

QoL-AD: QOL Scale in Alzheimer's disease; GAL: galantamine; NIM: nimodipine; PLA: placebo; * $p$-value: estimated using two-factors repeated measure ANOVA (treatment group and visit); ${ }^{\star \star} p$-value: estimated using single-factor repeated measure ANOVA (visit).

total sample (both GAL/NIM and GAL/PLA patients), assessing if 24-week therapy with GAL produces significant improvements in cognitive speed, QoL and other dementia clinically-relevant measures.

The patient component of the QoL-AD measure (patients' self-reported QoL) showed significant improvements from baseline to week 24 (difference of means=4.9; $\mathrm{p}=0.027$ ) when all GAL treated patients were combined in the analysis (regardless initial treatment arm). CNTB individual tests and caregivers versions of the QoL-AD questionnaire did not present significant differences between baseline and the end of follow-up (Tables 2 and 3). Regarding the secondary efficacy measures, GAL treatment led to significant improvements in ADAS-Cog (difference of mean=-3.9; $p=0.029)$ and MMSE (1.2; $p=0.037)$ at 24 weeks as compared to baseline values. Significant changes were not observed for CGI-I and NPI (Table 4).

\section{Adverse events}

Six patients discontinued the treatment due to adverse events (three in each group), five mostly because of nausea, vomiting and diarrhea, which were predominantly mild to moderate, and one due to respiratory distress (in the GLA/PLA arm), rated as severe by the investigator.

\section{DISCUSSION}

This is the first randomized, double-blind, multicenter clinical trial designed to prospectively evaluate the efficacy and safety of the association between a ChEI and NIM in patients with mixed dementia. The findings of our study showed significant improvement in both QoL-AD, ADASCog and MMSE scores at week 24, compared with baseline, among GAL treated patients (regardless the association with NIM), despite its small sample size. The association of NIM to GAL did not lead to any clinical advantage. We believe that these results may be relevant for current clinical practice and also for future research.

GAL has been tested in several randomized clinical trials for $\mathrm{AD}^{3,16,25,26}$ and has been also evaluated in a systematic review, which examined its efficacy and safety for patients

Table 4. Results for the secondary efficacy measures.

\begin{tabular}{|c|c|c|c|c|c|}
\hline Outcome measure & & GAL/NIM & GAL/PLA & Total sample & p-value \\
\hline \multirow[t]{3}{*}{ ADAS-Cog $(n=11)$} & Baseline & $26.4 \pm 11.2$ & $30.7 \pm 11.8$ & $28.7 \pm 11.2$ & \multirow{2}{*}{$0.135 *$} \\
\hline & 24-weeks & $25.0 \pm 9.7$ & $24.6 \pm 12.1$ & $24.8 \pm 10.5$ & \\
\hline & & Within-group change & & -3.9 & $0.029 * *$ \\
\hline \multirow[t]{7}{*}{ CGI-I at 24 weeks $(n=12)$} & Very much improved & $0(0 \%)$ & $0(0 \%)$ & $0(0 \%)$ & \multirow{7}{*}{$1.000^{*}$} \\
\hline & Much improved & $1(20 \%)$ & $2(25 \%)$ & $3(23.1 \%)$ & \\
\hline & Minimally improved & $3(60 \%)$ & $4(50 \%)$ & $7(53.8 \%)$ & \\
\hline & No change & $1(20 \%)$ & $1(12.5 \%)$ & $2(15.4 \%)$ & \\
\hline & Minimally worse & $0(0 \%)$ & $0(0 \%)$ & $0(0 \%)$ & \\
\hline & Much worse & $0(0 \%)$ & $0(0 \%)$ & $0(0 \%)$ & \\
\hline & Very much worse & $0(0 \%)$ & $0(0 \%)$ & $0(0 \%)$ & \\
\hline \multirow[t]{3}{*}{ NPI $(n=12)$} & Baseline & $23.4 \pm 8.1$ & $27.7 \pm 17.9$ & $25.9 \pm 14.3$ & \multirow{2}{*}{$0.765^{\star}$} \\
\hline & 24-weeks & $15 \pm 11.5$ & $21.7 \pm 16.9$ & $18.9 \pm 14.7$ & \\
\hline & & Within-group change & & -7.0 & $0.096^{* *}$ \\
\hline \multirow[t]{3}{*}{ MMSE $(n=12)$} & Baseline & $15.4 \pm 3.8$ & $16.6 \pm 2.6$ & $16.1 \pm 3.1$ & \multirow{2}{*}{$0.187 *$} \\
\hline & 24-weeks & $17.6 \pm 5.3$ & $17.1 \pm 3.7$ & $17.3 \pm 4.2$ & \\
\hline & & Within-group change & & 1.2 & $0.037 * *$ \\
\hline
\end{tabular}

ADAS-Cog: Alzheimer's disease Assessment Scale-Cognitive Subscale; CGI-I: Clinician Global Impression Improvement Scale; NPI: Neuropsychiatric Inventory; MMSE: Mini-Mental State Examination; GAL: galantamine; NIM: nimodipine; PLA: placebo; ${ }^{*} \mathrm{p}$-value: estimated using two-factors repeated measure ANOVA (treatment group and visit); ${ }^{*} p$-value: estimated using single-factor repeated measure ANOVA (visit). 
with vascular cognitive impairment, but also included studies enrolling mixed dementia patients ${ }^{4}$. Two studies were deemed eligible for the systematic review (GAL-INT-26 and GAL-INT6), the first assessing a population with probable vascular dementia $^{27}$ and the other, a mixed population of vascular dementia and $\mathrm{AD}$ with simultaneous CVD patients ${ }^{9.28}$.

In GAL-INT-6 study, patients with vascular dementia and $\mathrm{AD}$ with $\mathrm{CVD}$ showed greater clinical benefit over placebo on ADAS-Cog, clinician's interview-based impression of change plus caregiver input (CIBIC-plus), activities of daily living and on behavioral symptoms measures'. The GALINT-6 study observed similar benefits on ADAS-Cog among vascular dementia patients, but was not able to verify improvements in other efficacy measures. The GAL-INT-26 trial showed that GAL was superior to placebo for three of the four subtypes of VaD studied (multiple lacunar infarcts, extensive white matter disease and multiple territorial infarcts) in ADAS-cog improvement ${ }^{27}$. Interestingly, in our study most of the mixed dementia patients had subcortical vascular disease. These and other studies ${ }^{4,7,9,27,28}$ reported higher rates of nausea and vomiting in GAL treated participants, compared with placebo, consistent with our results and the generally favorable safety profile observed in previous studies in $\mathrm{AD}$ disease $\mathrm{e}^{5,25,26,29}$.

A systematic review ${ }^{3}$ of 15 trials evaluating the efficacy of NIM in $A D, C V D$ and mixed dementia found benefits of the NIM therapy on short-term outcomes of global and cognitive function, when results were pooled together, despite dementia specific etiology. Separate analysis of $\mathrm{AD}$ and CVD patients showed similar results. Given its mechanism of action, we hypothesized that co-administration with GAL could improve clinical outcomes in comparison to
GAL monotherapy in these patients. However, our results did not show any additional efficacy benefits of the association therapy.

The major limitation of our study was the small sample size. This was probably due to the short enrollment period and to the rigorous inclusion criteria that were adopted. The latter aimed to ensure the inclusion of patients truly presenting mixed dementia. An additional limitation is the somewhat large dropout rate, which may be explained by the clinical profile of the population, with several patients presenting comorbidities that impact tolerability and adherence to treatment.

In conclusion, in this exploratory, randomized, 24-week, placebo-controlled trial, GAL was well-tolerated and efficacious in improving QoL in patients with mixed dementia, in addition to its already known cognitive benefits. The combination of GAL to NIM did not demonstrate any apparent advantage, although this aspect should be further explored in larger studies.

\section{Acknowledgments}

We thank the investigators Irismar Reis and Vitor Tumas, the patients and their relatives for their participation in the study.

We thank the following colleagues, who contributed to data collection in the different participating centers: Cloyra Almeida, Etelvina Lucas dos Santos, Henrique Cerqueira Guimarães, Irene Moreira, Gilberto Alves, Margarete Borges, Patrícia Paes Araújo Fialho, Rogério Gomes Beato, Viviane Amaral Carvalho.

\section{References}

1. Korczyn AD. Mixed dementia - the most common cause of dementia. Ann New York Acad Sci 2002;977:129-134.

2. Herrera E, Caramelli P, Silveira ASB, Nitrini R. Epidemiologic survey of dementia in a community-dwelling Brazilian population. Alzheimer Dis Assoc Disord 2002;16:103-108.

3. López-Arrieta JM, Birks J. Nimodipine for primary degenerative, mixed and vascular dementia. Cochrane Database Syst Rev 2002;3:CD000147.

4. Craig D, Birks J. Galantamine for vascular cognitive impairment. Cochrane Database Syst Rev 2006;1:CD004746.

5. Loy C, Schneider L. Galantamine for Alzheimer's disease and mild cognitive impairment. Cochrane Database Syst Rev 2006;1:CD001747.

6. Gold G, Giannakopoulos P, Herrmann FR, Bouras C, Kövari E. Identification of Alzheimer and vascular lesion thresholds for mixed dementia. Brain 2007;130:2830-2836.

7. Erkinjuntti T, Gauthier S, Bullock R, et al. Galantamine treatment in Alzheimer's disease with cerebrovascular disease: responder analyses from a randomized, controlled trial (GAL-INT-6). J Psychopharmacol 2008;22:761-768.
Kumar V, Anand R, Messina J, Hartman R, Veach J. An efficacy and safety analysis of Exelon in Alzheimer's disease patients with concurrent vascular risk factors. Eur J Neurol 2000;7:159-169.

9. Erkinjuntti T, Kurz A, Gauthier S, Bullock R, Lilienfeld S, Damaraju CV. Efficacy of galantamine in probable vascular dementia and Alzheimer's disease combined with cerebrovascular disease: a randomised trial. Lancet 2002;359:1283-1290.

10. Kurz A. Galantamine improves cognitive and global abilities in Alzheimer's disease with cerebrovascular components and probable vascular dementia: preliminary results. Neurology 2001;56(Suppl):S340.

11. Tomassoni D, Lanari A, Silvestrelli G, Traini E, Amenta F. Nimodipine and its use in cerebrovascular disease: evidence from recent preclinical and controlled clinical studies. Clin Exp Hypertens 2008;30:744-766.

12. American Psychiatric Association. Diagnostic and Statistical Manual of Mental Disorders. Washington, DC: American Psychiatric Association, 1994.

13. Román GC, Tatemichi TK, Erkinjuntti T, et al. Vascular dementia: diagnostic criteria for research studies. Report of the NINDS-AIREN International Workshop. Neurology 1993;43:250-260. 
14. Folstein MF, Folstein SE, McHugh PR. Mini-mental state. A practical method for grading the cognitive state of patients for the clinician. J Psychiatr Res 1975;12:189-198.

15. Charchat H. Desenvolvimento de uma bateria de testes neuropsicológicos computadorizados para o diagnóstico precoce da Doença de Alzheimer. Dissertação de Mestrado, Universidade de São Paulo, 1999.

16. Caramelli P, Chaves ML, Engelhardt E, et al. Effects of galantamine on attention and memory in Alzheimer's disease measured by computerized neuropsychological tests: results of the Brazilian Multi-Center Galantamine Study (GAL-BRA-01). Arq Neuropsiquiatr 2004;62:379-384.

17. Logsdon RG, Gibbons LE, McCurry SM, Teri L. Quality of life in Alzheimer's disease: Patient and caregiver reports. J Mental Health Aging 1999;5:21-32.

18. Novelli MM, Dal Rovere HH, Nitrini R, Caramelli P. Cross-cultural adaptation of the quality of life assessment scale on Alzheimer disease. Arq Neuropsiquiatr 2005;63:201-206.

19. Rosen WG, Mohs RC, Davis KL. A new rating scale for Alzheimer's disease. Am J Psychiatry 1984;141:1356-1364.

20. Schultz RR, Siviero MO, Bertolucci PH. The cognitive subscale of the "Alzheimer's Disease Assessment Scale" in a Brazilian sample. Braz J Med Biol Res 2001;34:1295-1302.

21. Guy W. E.C.D.E.U. assessment manual for psychopharmacology. U.S. Dept. of Health, Education, and Welfare, Public Health Service, Alcohol, Drug Abuse, and Mental Health Administration, National Institute of Mental Health, Psychopharmacology Research Branch, Division of Extramural Research Programs, 1976.

22. Cummings JL, Mega M, Gray K, Rosenberg-Thompson S, Carusi DA, Gornbein J. The Neuropsychiatric Inventory: comprehensive assessment of psychopathology in dementia. Neurology 1994; $44: 2308-2214$

23. Camozzato AL, Kochhann R, Simeoni C, et al. Reliability of the Brazilian Portuguese version of the Neuropsychiatric Inventory (NPI) for patients with Alzheimer's disease and their caregivers. Int Psychogeriatr 2008;20:383-93.

24. Brucki SMD, Nitrini R, Caramelli P, Bertolucci PH, Okamoto $\mathrm{IH}$. Suggestions for utilization of the Mini-Mental State Examination in Brazil. Arq Neuropsiquiatr 2003;61:777-781.

25. Rodda J, Morgan S, Walker Z. Are cholinesterase inhibitors effective in the management of the behavioral and psychological symptoms of dementia in Alzheimer's disease? A systematic review of randomized, placebo-controlled trials of donepezil, rivastigmine and galantamine. Int Psychogeriatr 2009;21:813-824.

26. Lockhart IA, Mitchell SA, Kelly S. Safety and tolerability of donepezil, rivastigmine and galantamine for patients with Alzheimer's disease: systematic review of the "real-world" evidence. Dement Geriatr Cogn Disord 2009;28:389-403.

27. Auchus AP, Brashear HR, Salloway S, Korczyn AD, De Deyn PP, Gassmann-Mayer C. Galantamine treatment of vascular dementia: a randomized trial. Neurology 2007;69:448-458.

28. Kurz AF, Erkinjuntti T, Small GW, Lilienfeld S, Damaraju CRV. Longterm safety and cognitive effects of galantamine in the treatment of probable vascular dementia or Alzheimer's disease with cerebrovascular disease. Eur J Neurol 2003;10:633-640.

29. Kavanagh S, Howe I, Brashear HR, et al. Long-term response to galantamine in relation to short-term efficacy data: pooled analysis in patients with mild to moderate Alzheimer's disease. Curr Alzheimer Res 2011;8:175-186. 